\title{
Effect of chronic kidney disease on outcomes of total joint arthroplasty: a meta-analysis
}

\author{
Chang-Wan Kim ${ }^{1 \dagger}$, Hyun-Jung Kim² ${ }^{2 \dagger}$, Chang-Rack Lee ${ }^{1 *} \mathbb{D}$, Lih Wang ${ }^{3}$ and Seung Joon Rhee ${ }^{4}$
}

\begin{abstract}
Background: This meta-analysis was conducted to evaluate the differences in preoperative comorbidities, postoperative mortality, the rate of periprosthetic joint infection (PJI), and revision rate after total joint arthroplasty (TJA) between patients with chronic kidney disease (CKD)(CKD group) and patients with normal kidney function (non-CKD group).
\end{abstract}

Methods: We searched MEDLINE, EMBASE, and the Cochrane Library for studies assessing the effect of CKD on TJA outcome. This meta-analysis included studies that (1) compared the outcomes of TJA between the CKD and non-CKD groups; (2) compared the outcomes of TJA based on CKD stage; and (3) evaluated the risk factors for morbidity or mortality after TJA. We compared the mortality, PJI, and revision rate between CKD and non-CKD groups, and between dialysis-dependent patients (dialysis group) and non-dialysis-dependent patients (non-dialysis group).

Results: Eighteen studies were included in this meta-analysis. In most studies that assessed preoperative comorbidities, the number and severity of preoperative comorbidities were reported to be higher in the CKD group than in the non-CKD group. The risk of mortality was found to be higher in the CKD and dialysis groups compared with the respective control groups. In the studies based on administrative data, the unadjusted odds ratio (OR) of PJI was significantly higher in the CKD group than in the non-CKD group; however, no significant difference between the groups was noted in the adjusted OR. After total hip arthroplasty (THA), the risk of PJl was higher in the dialysis group than in the non-dialysis group. No significant difference was noted between the groups in the rate of PJ following total knee arthroplasty. The revision rate did not significantly differ between the CKD and non-CKD groups in the studies that were based on administrative data. However, the unadjusted OR was significantly higher in the dialysis group than in the non-dialysis group.

Conclusions: Preoperative comorbidities and mortality risk were higher in the CKD and dialysis groups than in their respective control groups. The risk of revision was greater in the dialysis group than in the non-dialysis group, and the risk of PJI in the dialysis group became even greater after THA. Surgeons should perform careful preoperative risk stratification and optimization for patients with CKD scheduled to undergo TJA.

Keywords: Chronic kidney disease, Dialysis, Arthroplasty, Outcomes, Morbidity, Mortality

\footnotetext{
* Correspondence: leechangrack@inje.ac.kr

Investigation performed at the Department of Orthopedic Surgery, Inje University Busan Paik Hospital

${ }^{\dagger}$ Chang-Wan Kim and Hyun-Jung Kim contributed equally to this work.

${ }^{1}$ Department of Orthopedic Surgery, Inje University Busan Paik Hospital, 75,

Bokji-ro, Busanjin-gu, Busan 47392, Republic of Korea

Full list of author information is available at the end of the article
}

(c) The Author(s). 2020 Open Access This article is distributed under the terms of the Creative Commons Attribution 4.0 International License (http://creativecommons.org/licenses/by/4.0/), which permits unrestricted use, distribution, and reproduction in any medium, provided you give appropriate credit to the original author(s) and the source, provide a link to the Creative Commons license, and indicate if changes were made. The Creative Commons Public Domain Dedication waiver (http://creativecommons.org/publicdomain/zero/1.0/) applies to the data made available in this article, unless otherwise stated. 


\section{Background}

Total knee arthroplasty (TKA) or total hip arthroplasty (THA) is widely performed in patients with end-stage arthritis worldwide. Several authors have reported good longterm clinical outcomes and survivorship after total joint arthroplasty (TJA) in the lower extremities [1-3]. However, some patients experience surgery-related complications, such as surgical site infection and implant loosening after TJA, as well as multiple medical complications that can lead to serious results, such as death. Several studies have reported that poor clinical outcomes after TJA are related to various risk factors, including surgeon-related and implant-related factors [4-7]. Because TJA is mainly performed in elderly patients, it is important to consider patient-related factors, such as preoperative comorbidities, when determining postoperative clinical outcomes. Correlation has been reported between comorbidities, such as cardiovascular disease, kidney disease, liver disease, and diabetes mellitus (DM), and various complications including mortality and periprosthetic joint infection (PJI) [8-10]. Chronic kidney disease (CKD) is defined as a reduction in glomerular filtration rate, albumin excretion, or both. The reported global prevalence rate of CKD is 8$16 \%$, and it is one of several comorbidities that may be present in patients undergoing TJA [11-14]. Renal osteodystrophy and long-term dialysis in CKD are associated with increased risk of joint arthropathy and osteonecrosis, which can increase the requirement for TJA [15-18]. As CKD is associated with long-term DM and hypertension, patients with these conditions are highly likely to have other comorbidities. It has been reported that DM, which is regarded as an important risk factor for CKD, is correlated with aseptic loosening and PJI $[10,19]$. CKD is also known to be correlated with cardiovascular mortality [13]. Therefore, the management of patients with CKD after TJA must include careful observation and treatment.

Mathew et al. [20] reported that CKD is an independent risk factor for mortality in patients undergoing noncardiac surgery. However, the effect of CKD on postoperative mortality and morbidity in patients who underwent TJA was not adequately investigated. Several studies reported correlation between CKD and TJA outcomes. Reports from earlier studies vary with regard to the effect of CKD on the risk of complications, such as mortality, PJI, and arthroplasty revision rate [15, 21-26]. However, no systematic review or meta-analysis of this relationship was conducted. Therefore, it is essential to perform a systematic review of the available studies on the effect of CKD on the clinical outcomes of TJA.

This meta-analysis was conducted to evaluate differences in preoperative comorbidities and postoperative mortality, rate of PJI, and revision rate after TJA between patients who have CKD (CKD group) and patients with normal kidney function group (non-CKD group). We hypothesized that the CKD group would have more preoperative comorbidities and greater risks of mortality, PJI, and revision after TJA than the non-CKD group.

\section{Methods \\ Literature search and information sources}

This study was implemented in accordance with the guidelines of the Preferred Reporting Items for Systematic Reviews and Meta-analyses statement and was based on the Cochrane review method. An independent medical librarian searched three databases (i.e., MEDLINE, EMBASE, and the Cochrane Library) from the dates of inception to 10 May 2019, to identify studies that evaluated the effect of CKD on the clinical outcomes of TJA. We used the following Medical Subject Heading (MeSH) terms and/or text words: ("Renal Insufficiency, Chronic"[Mesh] OR "Kidney Failure, Chronic"[Mesh] OR "Chronic Renal Insufficiencies"[TW] OR "Chronic Kidney Failure"[TW]) AND ("Arthroplasty, Replacement"[Mesh] OR "total joint arthroplasty"[TW] OR "Arthroplasty, Replacement, Knee"[Mesh] OR "Knee Replacement Arthroplasty"[TW] OR "Arthroplasty, Replacement, Hip"[Mesh] OR "Hip Replacement Arthroplasty"[TW]). The full search procedure is shown in the Additional file 1. After the initial database search, the references of relevant articles were manually searched to identify additional studies. There was no restriction on the language and year of publication. Because this study was a meta-analysis of published literature, permission from the institutional review board or informed consent was not required.

\section{Study selection}

This meta-analysis included studies that met the following criteria: (1) they compared TJA outcomes between patients with CKD and patients with normal kidney function, (2) they compared TJA outcomes based on the CKD stage or implementation of dialysis, and (3) they evaluated risk factors for morbidity or mortality after TJA using CKD as a variable. Review articles, case reports, and studies on hemiarthroplasty, partial replacement arthroplasty, or revision TJA, and studies that did not compare the clinical outcomes of TJA between patients with CKD and patients with normal kidney function were excluded from this analysis. For studies containing insufficient data for the evaluation of TJA outcomes, we sent an e-mail to the authors; studies were excluded from this analysis if we did not receive a response or obtain the necessary data. Furthermore, only studies that used clear terminology on disease severity and chronicity, such as CKD, chronic renal disease or failure, dialysis, end-stage renal disease (ESRD), and moderate to severe renal disease, were included in this analysis. Those that did not clearly indicate the severity or chronicity, such as kidney disease or renal disease, and those without a description of the definition of kidney 
disease or renal disease in the text were excluded from the meta-analysis.

Two reviewers independently screened the titles and abstracts of the searched studies and selected relevant studies. The decision to include the studies screened by title in the meta-analysis was confirmed through fulltext review.

\section{Assessment of methodological quality}

Two reviewers independently evaluated the methodological quality of the selected studies using the Newcastle-Ottawa scale for nonrandomized studies in a systematic review and/or meta-analysis; it comprised the following three criteria: selection of the study groups (four numbered items), comparability of the groups (one numbered item), and ascertainment of either the exposure or outcomes of interest for case-control or cohort studies (three numbered items). The Newcastle-Ottawa scale awards stars to the items in each criterion, based on the level of bias; the maximum number of stars that can be acquired is nine.

\section{Data extraction}

Using a predefined data extraction form, two reviewers independently extracted the following data from the included studies: first author, year of publication, study design, sample size, type of surgery (THA or TKA), average age at the time of surgery, average follow-up duration, preoperative comorbidity, mortality, infection, and revision. Data on PJI or deep infection were extracted. Data on wound problems, superficial infections, and surgical site infections were excluded.

\section{Statistical analysis}

A meta-analysis was conducted on the postoperative outcomes (mortality, PJI, and revision) between the CKD and non-CKD groups. Although CKD is categorized into five stages (stages 1-5) based on the estimated glomerular filtration rate (eGFR), only stages 3,4 , and 5 , which are characterized by eGFR less than $60 \mathrm{~mL} / \mathrm{min} / 1.73 \mathrm{~m}^{2}$, are considered as CKD. Dialysis is particularly vital for patients with stage 5 CKD (ESRD). To assess the impact of the severity of CKD on postoperative outcomes, a meta-analysis was also conducted between patients with CKD stage 5/ESRD and dialysis-dependent patients (dialysis group) and non-ESRD and non-dialysis-dependent patients (non-dialysis group). The dialysis and nondialysis groups of patients with CKD were not compared among the patients with CKD, but they were compared among all the patients who received TJA. In other words, the non-dialysis group also included patients with CKD who did not undergo dialysis. If studies separately reported both early and late complications after TJA, but did not report the raw data, only the data on early complications were used in the meta-analysis.

The meta-analysis was conducted by distinguishing between studies based on administrative data and studies based on hospital data. In the present study, hospital data refers to clinical data (e.g., serum creatinine level) recorded over the course of the patient's treatment in the hospital. In contrast, administrative data refers to registry data or claims data collected by government institutions and other organizations. A random effect model was used. The meta-analysis was conducted on the TJA outcomes reported by more than two studies. The odds ratio (OR) or hazard ratio (HR) of each outcome (mortality, PJI occurrence, and revision rate) and 95\% confidence intervals (CIs) were used in the metaanalysis. For studies that did not report the outcome using the OR, the OR was computed on the basis of the raw data from the study. Heterogeneity was assessed using the $I^{2}$ statistic: $I^{2}$ of $25 \%$ was regarded as low heterogeneity, $50 \%$ was regarded as moderate heterogeneity, and $75 \%$ was regarded as high heterogeneity. Forest plots were used to represent the outcomes of each study, pooled estimates of effect, and overall summary effects: $p$ values smaller than 0.05 were regarded as statistically significant. All statistical analysis was conducted using RevMan version 5.3 (Copenhagen, Nordic Cochrane Centre, The Cochrane Collaboration, 2014).

\section{Results \\ Study selection}

The study selection process is summarized in Fig. 1. Through literature searches, we found a total of 467 studies, including 80 in PubMed (MEDLINE), 371 in EMBASE, and 16 in the Cochrane Library. No further studies were found through manual searches. Following the removal of 89 duplicate studies, we conducted screening of the titles and abstracts of 378 studies and full-text review of the remaining 45 studies. Finally, 18 studies were included in this analysis.

\section{Study characteristics}

Among the 18 studies included in this analysis, 12 studies $[14,22-32]$ were based on administrative data and 6 studies $[15,21,33-36]$ on hospital data. Among the 18 studies, 4 studies $[23,27,29,31]$ reported the outcome of THA, 7 studies [22, 24, 28, 32-35] reported the outcome of TKA, and the remaining 7 studies $[14,15,21$, $25,26,30,36]$ reported the outcomes of both THA and TKA.

The characteristics of the studies included are summarized in Table 1. In most of the studies that were based on hospital data, CKD was defined by the eGFR, which was defined on the basis of the Modification of Diet in Renal Disease equation [37], as follows: eGFR ( $\mathrm{mL} / \mathrm{min} /$ 


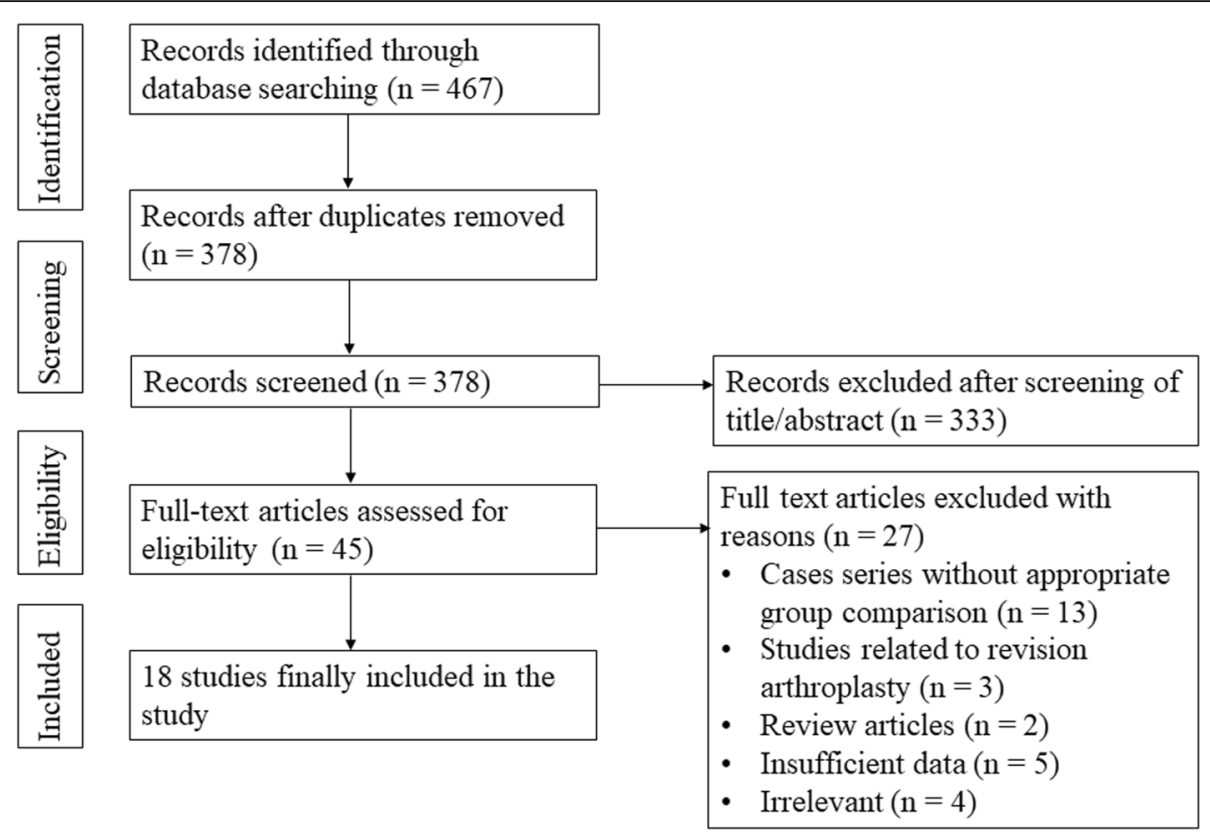

Fig. 1 Preferred reporting items for systematic reviews and meta-analyses flow diagram

$\left.1.73 \mathrm{~m}^{2}\right)=186.3 \times$ serum creatinine $(\mathrm{mg} / \mathrm{dL})^{-1.154} \times$ age (years $)^{-0.203} \times(0.742$ if the patient was female $)$. CKD stage was categorized in accordance with the clinical guidelines of the National Kidney Foundation, as follows [37]: CKD stage 1 (normal) for eGFR $\geq 90 \mathrm{~mL} / \mathrm{min} / 1.73$ $\mathrm{m}^{2}$; CKD stage 2 (mild) for eGFR $60-89 \mathrm{~mL} / \mathrm{min} / 1.73$ $\mathrm{m}^{2}$; CKD stage 3 (moderate) for eGFR $30-59 \mathrm{~mL} / \mathrm{min} /$ $1.73 \mathrm{~m}^{2}$; CKD stage 4 (severe) for eGFR $15-29 \mathrm{~mL} / \mathrm{min} /$ $1.73 \mathrm{~m}^{2}$; and CKD stage 5 for eGFR $<15 \mathrm{~mL} / \mathrm{min} / 1.73$ $\mathrm{m}^{2}$. Some studies indirectly reported the CKD stages of the research subjects using terminology such as chronic renal failure, ESRD, or moderate to severe renal disease. Other studies [38-40] did not clearly describe the definition or stage of CKD. One study defined CKD as preoperative creatinine $>1.5 \mathrm{mg} / \mathrm{L}$ [29]. In general, CKD is defined as eGFR $<60 \mathrm{~mL} / \mathrm{min} / 1.73 \mathrm{~m} 2$ [37]. In this study, patients with CKD stages 3, 4, and 5, and dialysisdependent patients, were included in the CKD group, whereas patients with CKD stages 1 or 2 were included in the non-CKD group. For studies that were based on administrative data, the International Classification of Diseases, ninth revision, Clinical Modification [41] was used for the selection of research subjects. However, some studies did not contain specific descriptions of the method used for selection of research subjects.

\section{Preoperative morbidity}

In 11 studies [14, 15, 22-26, 30, 33, 34, 36], the comorbidities or health status of patients in the CKD group before TJA were assessed using a variety of methods, including the American Society of Anesthesiologists (ASA) physical status score, the Charlson comorbidity index [42], and the Elixhauser comorbidity index [43]. Some studies reported only the frequencies of certain diseases, such as DM and cardiovascular disease. Hematologic status was evaluated on the basis of hemoglobin level, hematocrit level, white blood cell count, and platelet count.

Although the studies in this meta-analysis reported that different diseases had a relatively high prevalence in the CKD group compared with the prevalence in the nonCKD group, most reported that the CKD group had more preoperative comorbidities. The types of preoperative comorbidity evaluated differed among studies. In summary, cardiovascular disease, valvular disease, congestive heart failure, DM, rheumatoid arthritis, and peripheral vascular disease were more prevalent in the CKD group. Additionally, the CKD group had lower hemoglobin levels and higher ASA scores, and greater alcohol abuse and smoking frequency, relative to the non-CKD group.

\section{Mortality}

There were 13 studies [14, 15, 21-26, 29, 30, 34-36] that compared mortality after TJA between CKD and non-CKD groups or between dialysis and non-dialysis groups: among them, 8 studies were based on administrative data and 5 studies on hospital data. Metaanalysis of mortality in studies based on administrative data showed that the risk of mortality was significantly greater in the CKD group than that in the non-CKD group (Fig. 2a and b); the unadjusted OR was 1.93 (95\% CI, 1.67-2.24; $\left.p<0.00001 ; I^{2}, 25 \%\right)$, and the adjusted OR was 1.89 (95\% CI, 1.63-2.19; $p<0.00001 ; I^{2}, 10 \%$ ). 
Table 1 Study characteristics

\begin{tabular}{|c|c|c|c|c|c|c|c|c|c|c|c|}
\hline Author & Year & Country & Study design & Database & $\begin{array}{l}\text { Type of } \\
\text { surgery }\end{array}$ & $\begin{array}{l}\text { Mean age } \\
\text { (years) }\end{array}$ & $\begin{array}{l}\text { Total } \\
\text { sample size }\end{array}$ & CKD stage & $\begin{array}{l}\text { Number } \\
\text { of cases in } \\
\text { CKD group }\end{array}$ & $\begin{array}{l}\text { Number of } \\
\text { cases in } \\
\text { control group }\end{array}$ & NOS \\
\hline Bedard [27] & 2018 & USA & $\begin{array}{l}\text { Retrospective } \\
\text { case-control }\end{array}$ & $\begin{array}{l}\text { Humana } \\
\text { database }\end{array}$ & THA & $\mathrm{N} / \mathrm{A}$ & 17,695 & N/A & 2288 & 15,407 & 6 \\
\hline Bedard [28] & 2018 & USA & $\begin{array}{l}\text { Retrospective } \\
\text { case-control }\end{array}$ & $\begin{array}{l}\text { Humana } \\
\text { database }\end{array}$ & TKA & N/A & 35,894 & N/A & 4551 & 31,343 & 6 \\
\hline $\begin{array}{l}\text { Boniello } \\
\text { [29] }\end{array}$ & 2018 & USA & $\begin{array}{l}\text { Retrospective } \\
\text { cohort study }\end{array}$ & ACS-NSQIP & THA & $\geq 80$ & & Preop $\mathrm{Cr}>1.5 \mathrm{mg} / \mathrm{L}$ & 1759 & 65,080 & 7 \\
\hline $\begin{array}{l}\text { Cavanaugh } \\
{[30]}\end{array}$ & 2016 & USA & $\begin{array}{l}\text { Retrospective } \\
\text { cohort study }\end{array}$ & NIS & THA, TKA & $\begin{array}{l}\text { CKD: } 71.9 \\
\text { non-CKD: } 65.6\end{array}$ & $1,014,686$ & $\begin{array}{l}\text { CKD stage 3-4, RT, } \\
\text { dialysis, and ESRD }\end{array}$ & 36,308 & 978,378 & 7 \\
\hline Deegan [21] & 2014 & USA & $\begin{array}{l}\text { Retrospective } \\
\text { cohort study }\end{array}$ & $\begin{array}{l}\text { Geisinger } \\
\text { Health System }\end{array}$ & THA, TKA & 72 & 779 & CKD stage $1,2,3$ & 402 & 377 & 8 \\
\hline Erkocak [15] & 2016 & USA & $\begin{array}{l}\text { Retrospective } \\
\text { cohort study }\end{array}$ & Hospital data & THA, TKA & $\begin{array}{l}\text { CKD: } 67.8 \\
\text { Control: } 67.2\end{array}$ & 1077 & N/A & 359 & 718 & 8 \\
\hline Kildow [31] & 2017 & USA & $\begin{array}{l}\text { Retrospective } \\
\text { cohort study }\end{array}$ & Medicare & THA & $\mathrm{N} / \mathrm{A}$ & 91,467 & $\begin{array}{l}\text { CKD stage 1-4, } \\
\text { hemodialysis, RT }\end{array}$ & 29,689 & 61,778 & 8 \\
\hline Kuo [33] & 2017 & Taiwan & $\begin{array}{l}\text { Retrospective } \\
\text { cohort study }\end{array}$ & Hospital data & TKA & $\begin{array}{l}\text { CKD: } 72.1 \\
\text { Non-CKD: } 71.0\end{array}$ & 615 & eGFR $<60$ & 205 & 410 & 8 \\
\hline Kuo [22] & 2017 & Taiwan & $\begin{array}{l}\text { Retrospective } \\
\text { cohort study }\end{array}$ & NHIRD & TKA & $\begin{array}{l}\text { CKD: } 71.6 \\
\text { Non-CKD: } 70.3\end{array}$ & 13,844 & N/A & 1459 & 12,385 & 8 \\
\hline $\begin{array}{l}\text { Lizaur-Utrilla } \\
\text { [34] }\end{array}$ & 2016 & Spain & $\begin{array}{l}\text { Retrospective } \\
\text { case-control }\end{array}$ & Hospital data & TKA & $\begin{array}{l}\text { ESRD: } 69.3 \\
\text { Control: } 70.1\end{array}$ & 45 & ESRD (dialysis or RT) & 15 & 30 & 7 \\
\hline Marya [35] & 2016 & India & $\begin{array}{l}\text { Retrospective } \\
\text { case-control }\end{array}$ & Hospital data & $\begin{array}{l}\text { Bilateral } \\
\text { simultaneous } \\
\text { TKA }\end{array}$ & 65.8 & 556 & $\begin{array}{l}\text { Moderate-to-severe } \\
\text { renal disease }\end{array}$ & 11 & N/A & 7 \\
\hline $\begin{array}{l}\text { McCleery } \\
{[32]}\end{array}$ & 2010 & UK & $\begin{array}{l}\text { Retrospective } \\
\text { cohort study }\end{array}$ & $\begin{array}{l}\text { Scottish } \\
\text { Arthroplasty } \\
\text { Project }\end{array}$ & TKA & N/A & 59,288 & $\begin{array}{l}\text { Renal failure, RT, } \\
\text { dialysis }\end{array}$ & 3718 & N/A & 7 \\
\hline Miric [23] & 2014 & USA & $\begin{array}{l}\text { Retrospective } \\
\text { cohort study }\end{array}$ & TJRR & THA & 66 & 18,663 & CKD stage $3,4,5$ & 1269 & 17,394 & 8 \\
\hline Miric [24] & 2014 & USA & $\begin{array}{l}\text { Retrospective } \\
\text { cohort study }\end{array}$ & TJRR & TKA & 67 & 37,482 & CKD stage $3,4,5$ & 2686 & 34,796 & 8 \\
\hline $\begin{array}{l}\text { Nikkinen } \\
{[36]}\end{array}$ & 2019 & Finland & $\begin{array}{l}\text { Retrospective } \\
\text { cohort study }\end{array}$ & Hospital data & THA, TKA & $\begin{array}{l}\text { Moderated to } \\
\text { severe CKD: } 81 \\
\text { Mild CKD: } 77 \\
\text { Normal kidney } \\
\text { function: } 71\end{array}$ & 807 & eGFR $<60$ & 109 & 698 & 7 \\
\hline $\begin{array}{l}\text { Patterson } \\
{[25]}\end{array}$ & 2018 & USA & $\begin{array}{l}\text { Retrospective } \\
\text { cohort study }\end{array}$ & ACS-NSQIP & THA, TKA & $\mathrm{N} / \mathrm{A}$ & $\begin{array}{l}\text { THA: } \\
129370 \\
\text { TKA:214005 }\end{array}$ & Dialysis & $\begin{array}{l}\text { THA:306 } \\
\text { TKA:339 }\end{array}$ & $\begin{array}{l}\text { THA:129064 } \\
\text { TKA:213666 }\end{array}$ & 8 \\
\hline $\begin{array}{l}\text { Ponnusamy } \\
{[26]}\end{array}$ & 2015 & USA & $\begin{array}{l}\text { Retrospective } \\
\text { cohort study }\end{array}$ & NIS & THA, TKA & $\begin{array}{l}\text { - THA } \\
\text { Non-dialysis: } \\
65.2 \\
\text { Dialysis: } 63.2 \\
\text { - TKA } \\
\text { Non-dialysis: } \\
66.8 \\
\text { Dialysis: } 66.7\end{array}$ & $\begin{array}{l}\text { THA: } \\
\text { 2006522 } \\
\text { TKA: } \\
4182887\end{array}$ & ESRD & $\begin{array}{l}\text { THA: } 1251 \\
\text { TKA: } 1683\end{array}$ & $\begin{array}{l}\text { THA: } 2005271 \\
\text { TKA: } 4181204\end{array}$ & 7 \\
\hline Warth [14] & 2015 & USA & $\begin{array}{l}\text { Retrospective } \\
\text { cohort study }\end{array}$ & ACS NSQIP & THA, TKA & $\begin{array}{l}\text { Mild or normal } \\
\text { CKD: } 70.7 \\
\text { Moderate or } \\
\text { severe CKD: } \\
72.6\end{array}$ & 25,116 & eGFR $<60$ & 12,558 & 12,558 & 8 \\
\hline
\end{tabular}

ACS-NSQIP American College of Surgeons-National Surgical Quality Improvement Program, CKD chronic kidney disease, Cr creatinine, CRF chronic renal failure, eGFR estimated glomerular filtration rate $\left(\mathrm{mL} / \mathrm{min} / 1.73 \mathrm{~m}^{2}\right)$, ESRD end-stage renal disease, $N / A$ not available, NHIRD National Health Insurance Research Database, NIS Nationwide inpatient sample, NOS Newcastle-Ottawa Scale (expressed as the number of stars assigned), preop preoperative, $R T$ renal transplantation, $T H A$ total hip arthroplasty, TJRR Total Joint Replacement Registry, TKA total knee arthroplasty, USA United States of America, UK United Kingdom

The HR of mortality was also significantly higher in the CKD group than that in the non-CKD group. The unadjusted $\mathrm{HR}$ was $2.43(95 \% \mathrm{CI}, 1.82-3.24 ; p<$ $\left.0.00001 ; I^{2}, 64 \%\right)$, and the adjusted HR was $1.45(95 \%$ CI, $\left.1.02-2.05 ; p=0.04 ; I^{2}, 81 \%\right)$. The dialysis group had significantly greater mortality than the nondialysis group after both THA (adjusted OR, 4.20; 95\% CI, $1.83-9.66 ; p=0.0007 ; I^{2}, 48 \%$ ) and TKA (adjusted OR, 2.95; 95\% CI, 1.29-6.76; $p<0.01 ; I^{2}, 0 \%$; Fig. 3). 


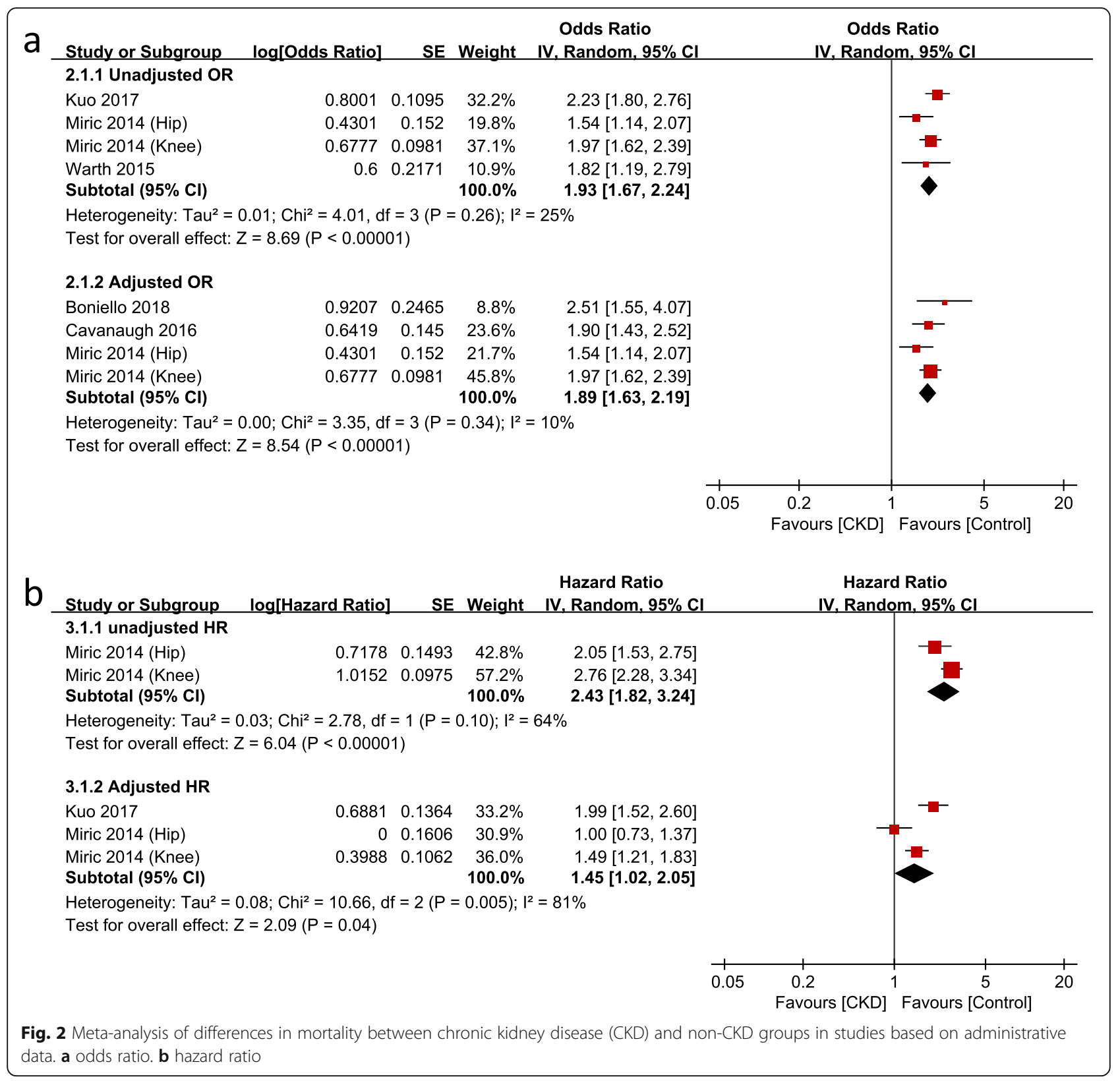

Meta-analysis of mortality in studies based on hospital data showed that respective risks of mortality were significantly greater in the CKD and dialysis groups than in the non-CKD (unadjusted OR, 5.38; 95\% CI, 1.12-25.82; $p=0.004 ; I^{2}, 66 \%$ ) and non-dialysis groups (unadjusted OR, 3.82; 95\% CI, 1.20-12.11; $p=0.02 ; I^{2}$, 0\%; Fig. 4).

\section{Periprosthetic joint infection}

There were 11 studies [14, 15, 21-25, 31-34] that evaluated the occurrence of PJI after TJA in the CKD group: among them, 7 studies were based on administrative data and 4 studies on hospital data. Meta-analysis of studies based on administrative data showed that the risk of PJI was significantly greater in the CKD group than in the non-CKD group (unadjusted OR, 1.37; 95\% CI, 1.16-1.62; $p=0.0002 ; I^{2}, 0 \%$; Fig. 5); however, the adjusted OR was not significant. After THA, the dialysis group had greater risk of PJI than the nondialysis group (unadjusted OR, 3.50; 95\% CI, 1.54-7.95; $p=$ $0.003 ; I^{2}, 24 \%$; Fig. 6). The difference was not significant between groups after TKA. Meta-analysis of studies based on hospital data showed no significant differences between the CKD and non-CKD groups or between the dialysis and nondialysis groups in terms of the occurrence of PJI (Fig. 7).

\section{Revision}

Nine studies [14, 21, 23, 24, 27, 28, 31, 32, 34] evaluated the revision rate after TJA in the CKD group. Among them, seven studies were based on administrative data 


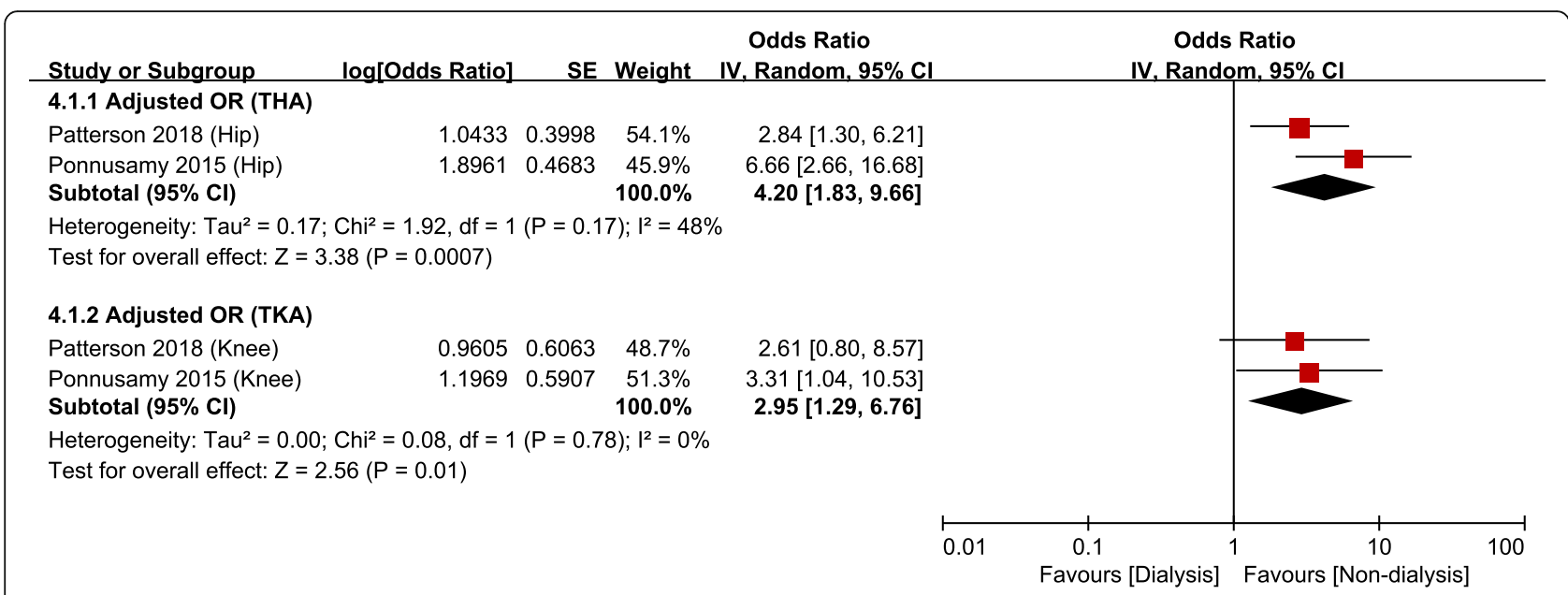

Fig. 3 Meta-analysis of differences in mortality between dialysis and non-dialysis groups in studies based on administrative data

and two studies on hospital data. However, metaanalysis could only be conducted on the studies based on administrative data: this analysis showed no significant differences in the revision rate between the CKD and non-CKD groups (Fig. 8a and b). The risk of revision in the ESRD/dialysis group was significantly greater than that in the non-dialysis group (unadjusted OR, 2.15; 95\% CI, 1.77-2.62; $p<0.00001 ; I^{2}$, 0\%; Fig. 9).

\section{Discussion}

In this meta-analysis, patients with $\mathrm{CKD}$ had more preoperative comorbidities and more severe preoperative comorbidities and higher risk of mortality after TJA, compared with patients with normal kidney function. Patients with severe CKD (i.e., ESRD) and dialysis-dependent patients had more risk of PJI and revision surgery.

CKD is defined as kidney damage or glomerular filtration rate lower than $60 \mathrm{~mL} / \mathrm{min} / 1.73 \mathrm{~m}^{2}$ for $\geq 3$ months; it poses a high risk of joint arthropathy or osteonecrosis secondary to renal osteodystrophy or long-term dialysis. Therefore, TJA is commonly performed in patients with CKD $[11,14,15,18,44]$. Because CKD is related to DM and hypertension, patients with CKD presumably have greater preoperative comorbidities and worse postoperative clinical outcomes, compared with patients with normal kidney function. A previous systematic review reported that $\mathrm{CKD}$ increases the risks of postoperative

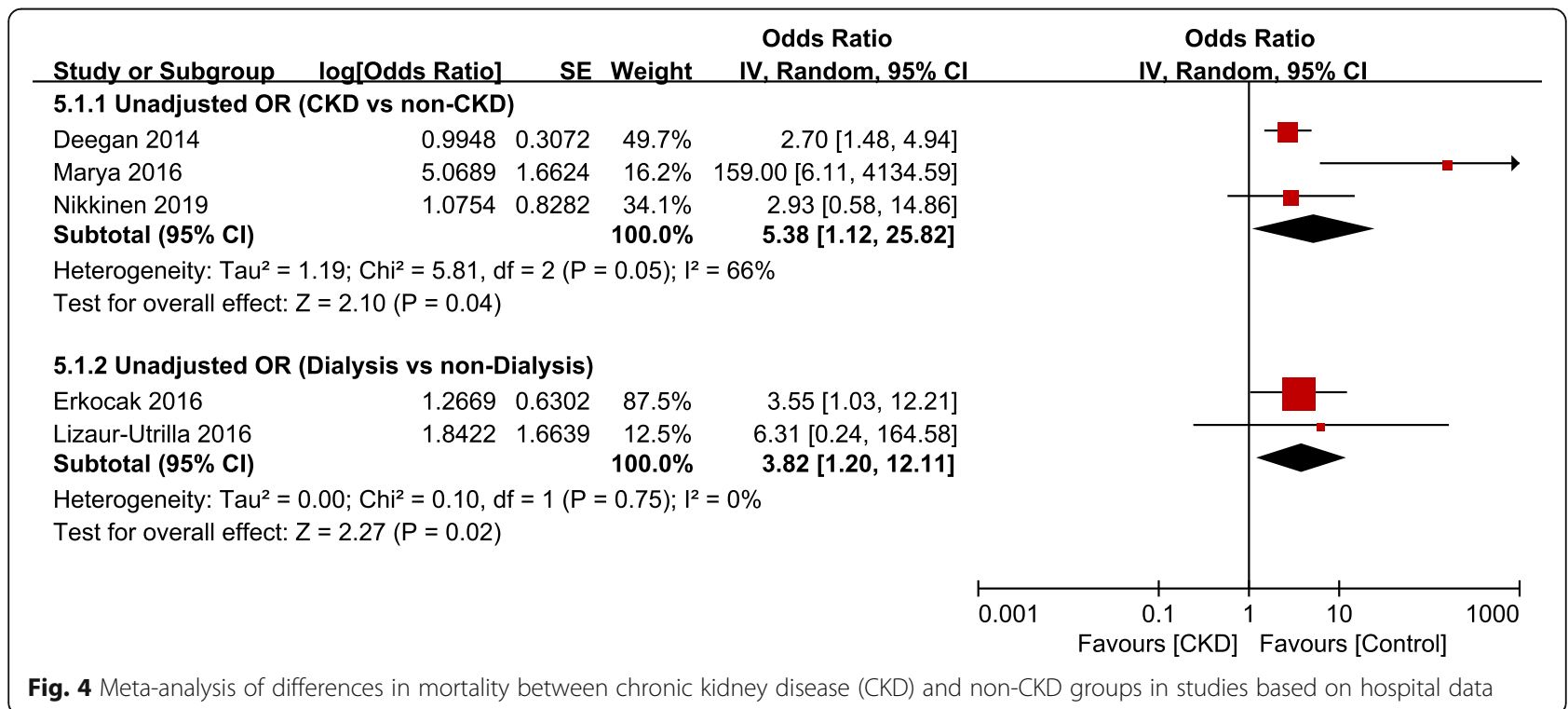




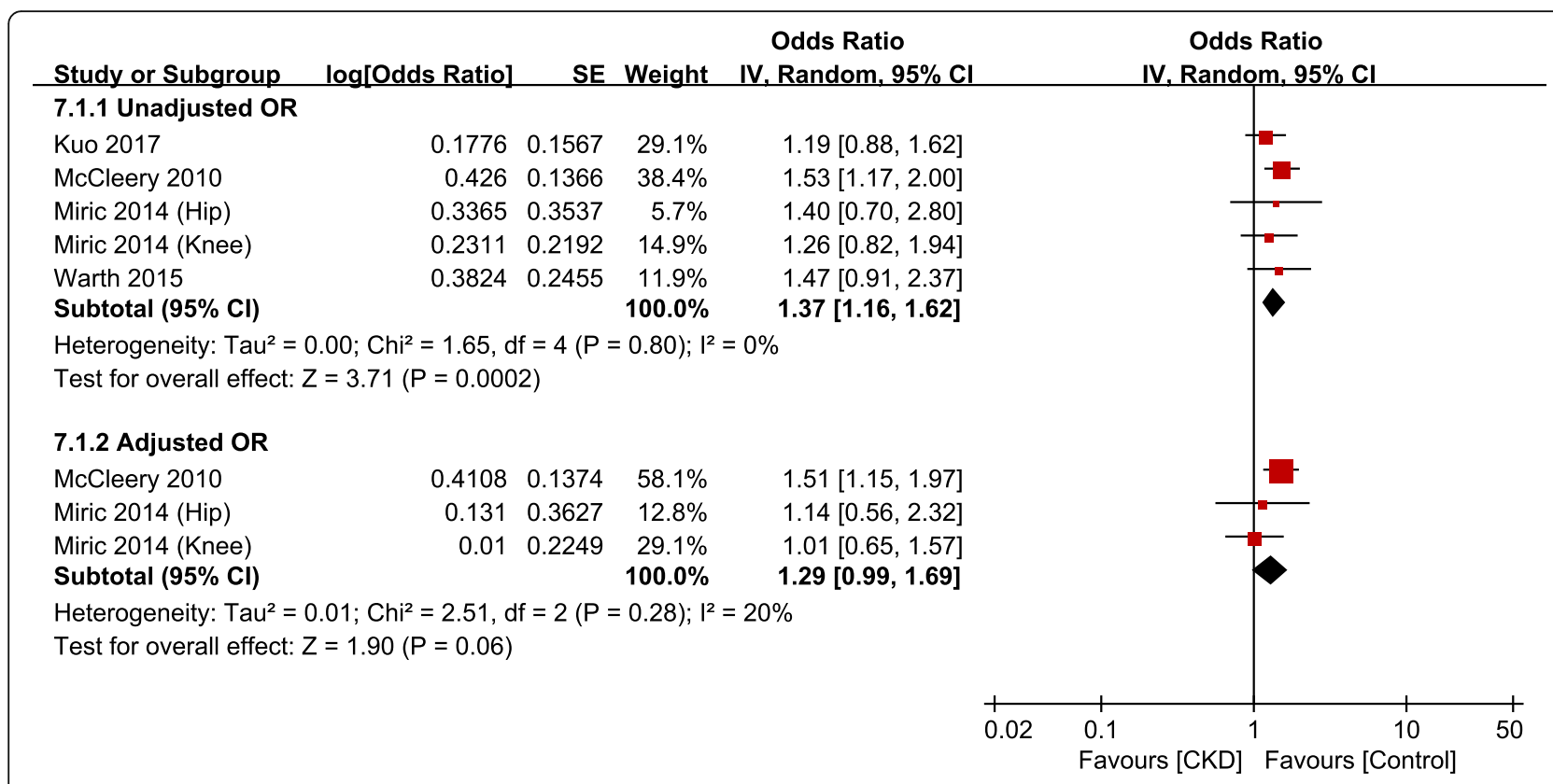

Fig. 5 Meta-analysis of differences in periprosthetic joint infection (PJI) between chronic kidney disease (CKD) and non-CKD groups in studies based on administrative data

death or cardiovascular events among non-cardiacsurgery patients [20]. Although the effects of CKD on the outcomes of TJA have been reported in several studies, to the best of our knowledge, no systematic review or meta-analysis on this topic has yet been conducted. The value of the present meta-analysis is that it might enable surgeons to predict the prognosis of patients with CKD after TJA.

To assess the impact of CKD on TJA outcome, differences in the numbers and severities of comorbidities between CKD and non-CKD groups must be assessed. More preoperative comorbidities or more severe preoperative comorbidities will likely affect TJA outcome. Most studies in this meta-analysis reported that the CKD group had a relatively high prevalence of cardiovascular disease, DM, and peripheral vascular disease, which can be attributed to the relationships between CKD and DM and hypertension. Moreover, when compared with the non-CKD group, the CKD group exhibited higher prevalence of liver disease, rheumatoid

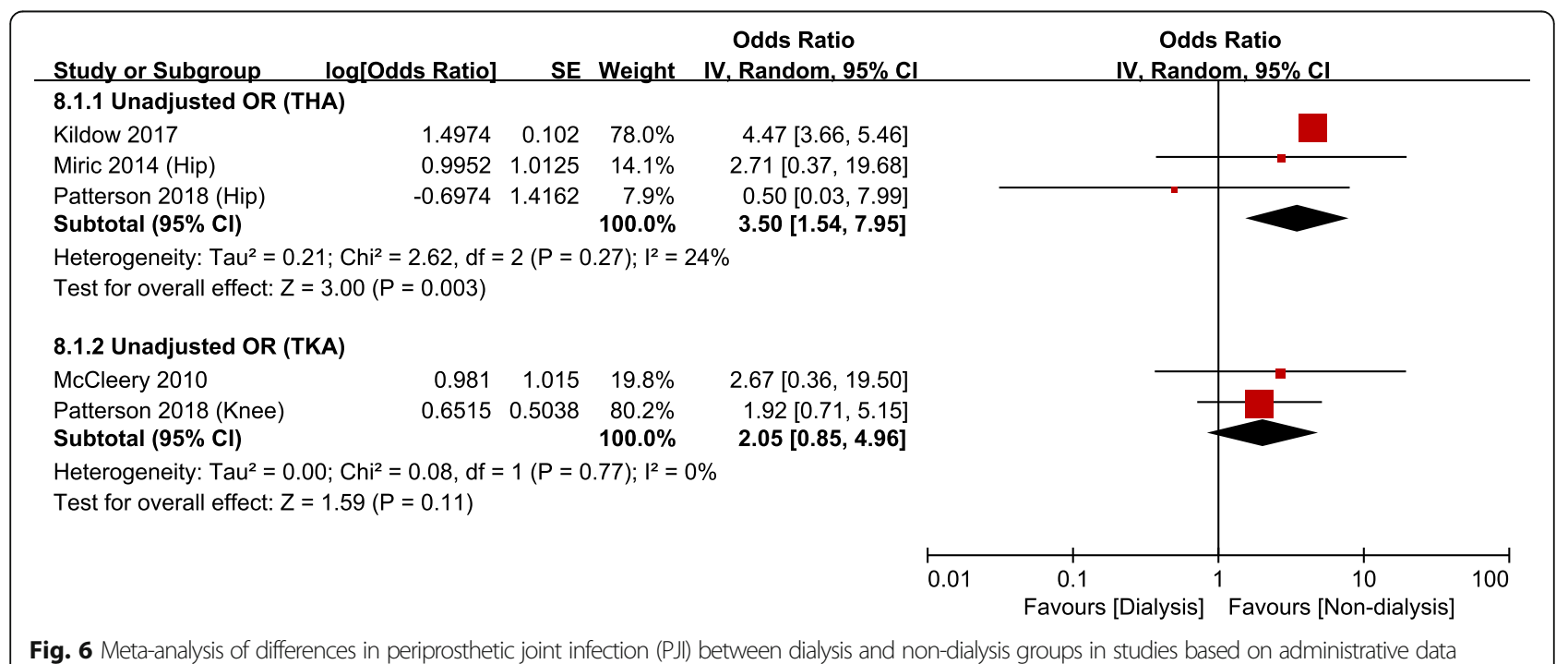




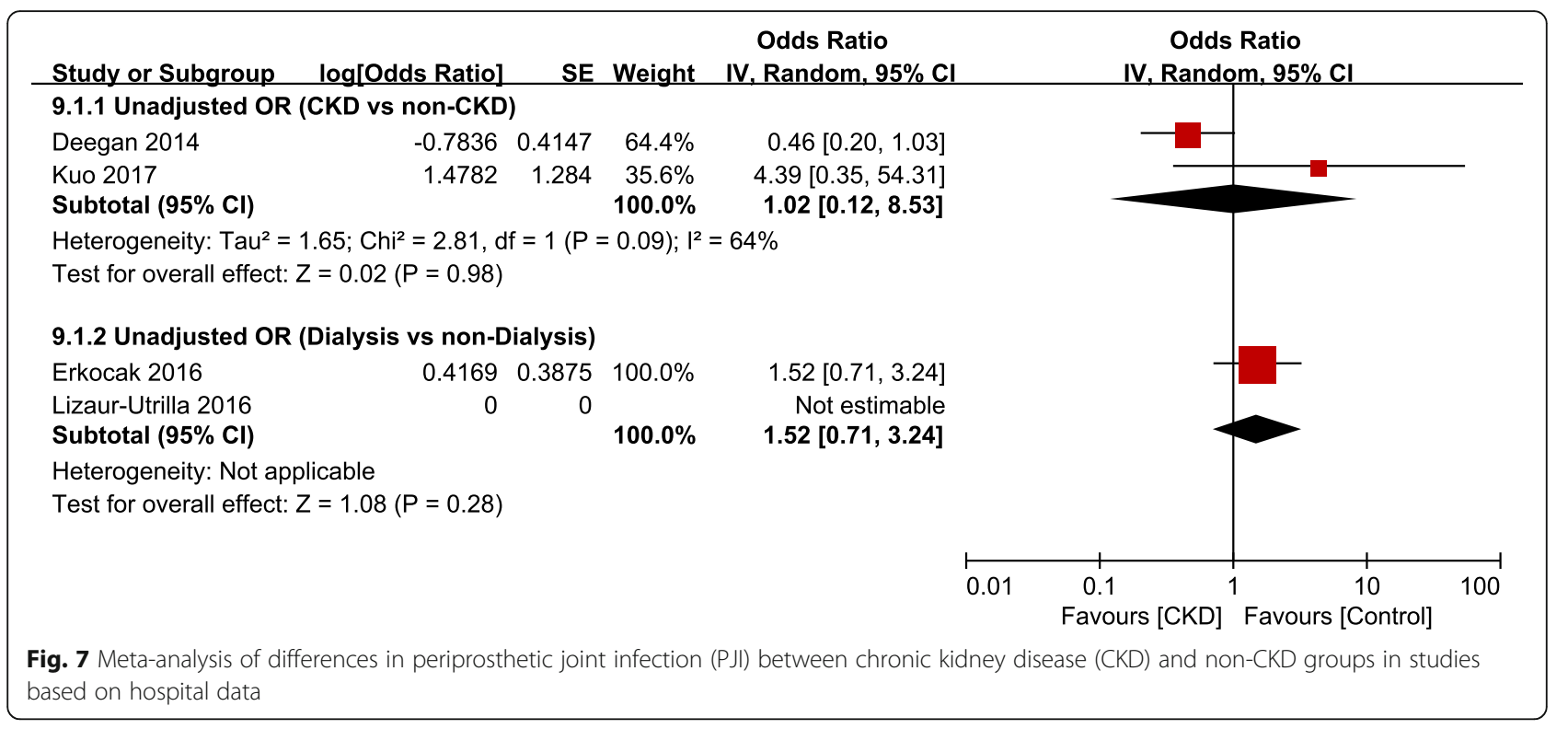

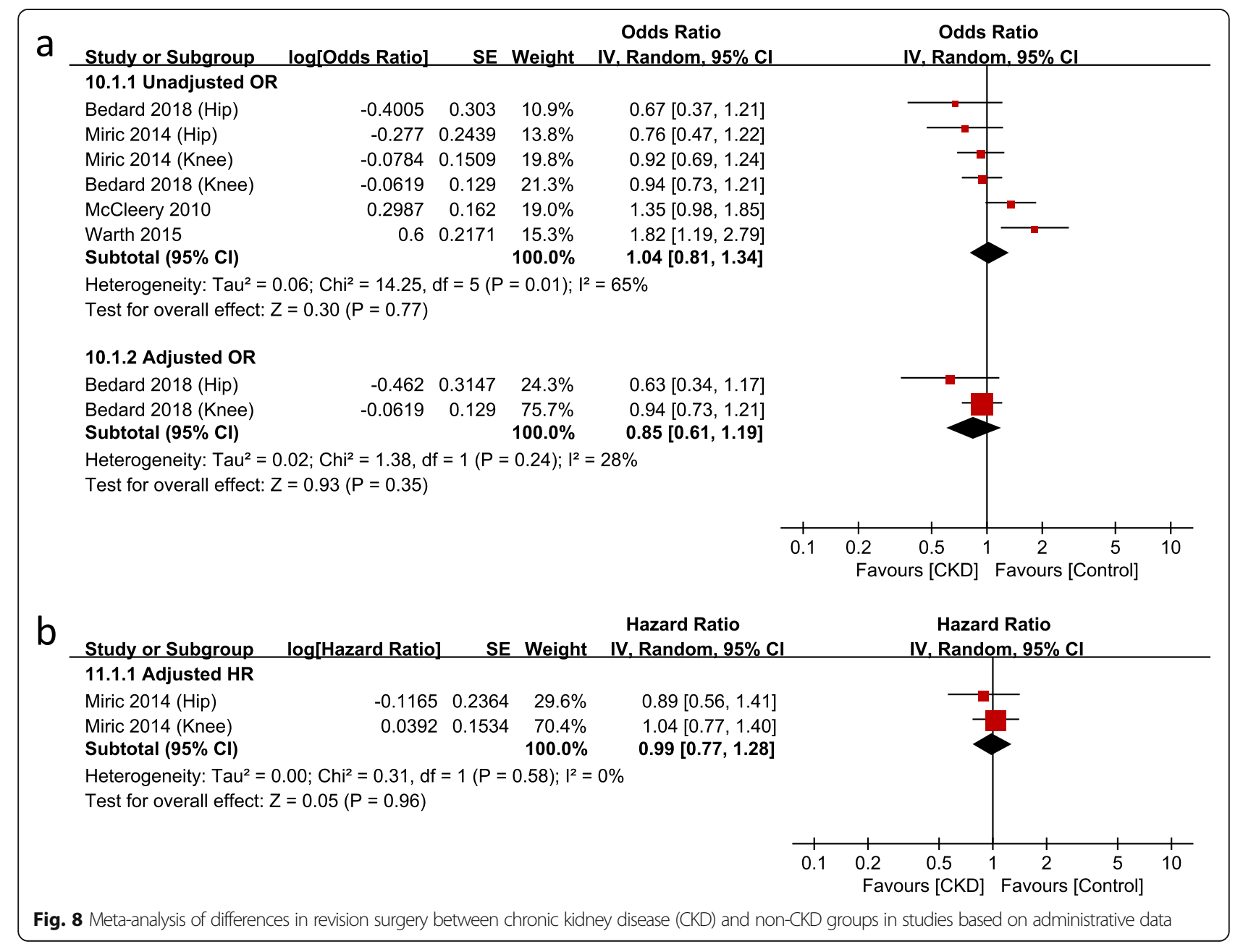




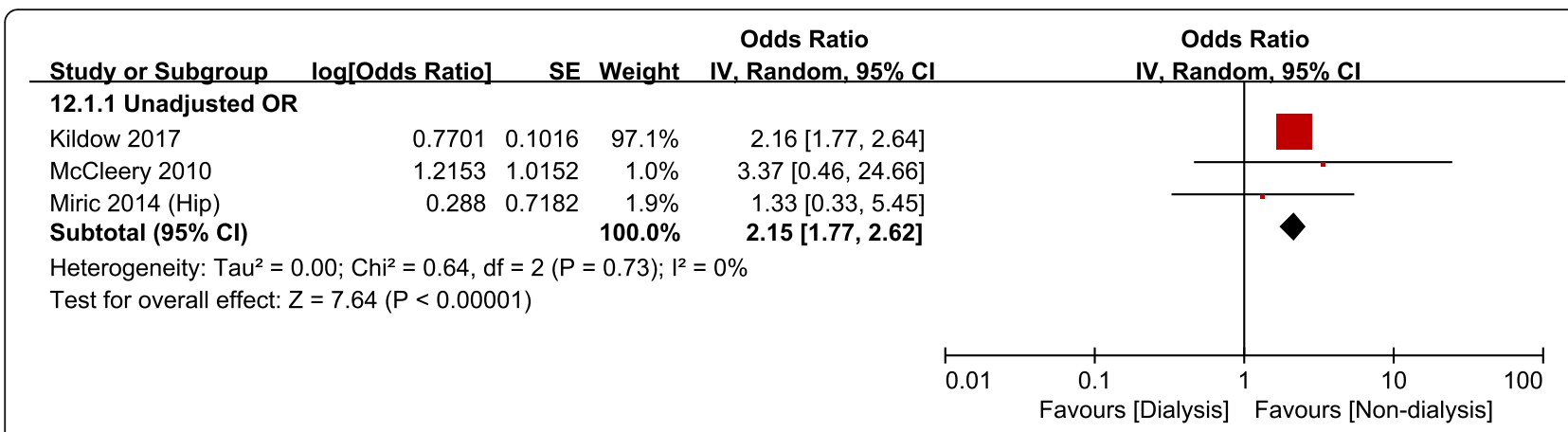

Fig. 9 Meta-analysis of differences in revision surgery between dialysis and non-dialysis groups in studies based on administrative data

arthritis, gout, alcohol abuse, and smoking, and had higher ASA and Charlson comorbidity scores and lower hemoglobin. Overall, although the tools used for evaluation of preoperative comorbidities varied among the studies, the CKD group had more comorbidities and more severe comorbidities than the non-CKD group.

Whether the presence of CKD is an independent risk factor for mortality in TJA is currently controversial. The current meta-analysis showed that the CKD and dialysis groups had greater mortality after TJA than the non-CKD and non-dialysis groups, respectively, regardless of the source of the data (hospital or administrative). More severe preoperative comorbidities are the greatest contributor to the greater mortality rate among patients with moderate to severe CKD, relative to patients with normal kidney function or mild CKD. After adjustment for diverse confounder effects, such as age and the presence of DM, however, it was difficult to conclude whether the presence of CKD itself was a risk factor for the high mortality rate. In this analysis, most of the studies based on administrative data controlled for confounders. However, most of the studies based on administrative data that we included in our metaanalysis controlled for confounders in their analyses. Furthermore, there was heterogeneity among the studies included. Considering these points, further studies are recommended that can clarify whether the presence of CKD is an independent predictor of mortality in TJA.

Many studies have reported correlation between the presence of CKD and the occurrence of infection after TJA. A number of factors, including nutritional deficiencies, anemia, metabolic imbalance, poor circulation, and reduced immunity, have been reported to affect the occurrence of PJI among patients with CKD [15, 30, 45]. Meta-analysis of studies based on administrative data showed that after THA, the CKD group had higher unadjusted odds of PJI than the non-CKD group, whereas the dialysis group had higher unadjusted odds of PJI than the non-dialysis group. Meta-analysis of studies based on hospital data showed no significant differences between the CKD and non-CKD groups. Considering the low incidence of PJI after TJA and the small number of studies based on hospital data, however, the results of meta-analysis of studies based on administrative data will have higher reliability. Therefore, the presence of CKD can be regarded as a risk factor for PJI after TJA.

In terms of revision, the dialysis group showed significantly higher odds of revision than the non-dialysis group in this study, whereas there was no significant difference between the CKD and non-CKD groups. The severity of CKD presumably affected the revision rate. Apart from medical comorbidities and the occurrence of PJI, the dialysis group showed a higher possibility of revision than the non-dialysis group for a variety of reasons, such as reduced osseointegration due to poor bone quality, implant loosening, or periprosthetic fracture [30, 46]. Considering the heterogeneity among studies included in this analysis and the short follow-up duration of the studies included, which interfered with evaluation of the revision rate, it is difficult to conclude whether the revision rate in patients with moderate CKD differs from that in patients with normal kidney function or mild CKD. To evaluate the effect of CKD on the rates of PJI and revision, high-quality studies that control for confounders are recommended in the future.

This study had several limitations. First, most studies were conducted in developed countries, such as the USA and European nations. Therefore, it is difficult to generalize the results of this study to developing countries. Second, the research subjects included in this study had various stages of CKD. Postoperative outcomes should be evaluated on the basis of CKD stage, to accurately assess the effect of the presence of CKD on TJA outcomes. However, most studies included in this metaanalysis did not present outcomes based on CKD stage. Nevertheless, depending on the severity of disease, TJA outcomes could be indirectly evaluated through the comparison of outcomes between dialysis and nondialysis groups. Third, surgical types and techniques varied among studies. Although subgroup analysis was 
conducted on the basis of the type of surgery, it was insufficient to draw conclusions on correlation between the type of surgery and the outcomes reported. Last, on comparing the dialysis and non-dialysis groups, patients with CKD who did not receive dialysis were included in the non-dialysis group. This group distinction should be considered when interpreting the present results. Comparison within the CKD group between patients who underwent dialysis and those who did not could not be performed in the present study because of the lack of data.

\section{Conclusions}

Preoperative comorbidity and mortality risk were greater in the CKD and dialysis groups than in their respective control groups. The risk of revision was greater in the dialysis group than in the non-dialysis group, and the risk of PJI in the dialysis group became even greater after THA. Surgeons should perform careful preoperative risk stratification and optimization for patients with CKD scheduled to undergo TJA.

\section{Supplementary information}

Supplementary information accompanies this paper at https://doi.org/10. 1186/s43019-020-0029-8.

Additional file 1. Search terms.

\section{Abbreviations}

ASA: American Society of Anesthesiologists; Cl: Confidence interval; CKD: Chronic kidney disease; DM: Diabetes mellitus; eGFR: Estimated glomerular filtration rate; ESRD: End-stage renal disease; HR: Hazard ratio; MeSH: Medical subject heading; OR: Odds ratio; PJl: Periprosthetic joint infection; THA: Total hip arthroplasty; TJA: Total joint arthroplasty; TKA: Total knee arthroplasty

\section{Acknowledgements}

We thank Na-Jin Kim from the Medical Library, College of Medicine, The Catholic University of Korea, for performing literature searches.

\section{Authors' contributions}

CWK: conception and study design, manuscript revision. HJK: study design, data analysis and interpretation. CRL: conception and study design, manuscript writing and revision, collection of data, data analysis and interpretation. LW: manuscript revision, data analysis and interpretation. SJR manuscript revision, data analysis and interpretation. All authors read and approved the final manuscript.

\section{Funding}

None.

\section{Availability of data and materials}

Not applicable.

\section{Ethics approval and consent to participate}

This is a systematic review and meta-analysis of the literature and no ethical approval was necessary for this study. No informed consent was necessary for the study.

\section{Consent for publication}

Not applicable.

\section{Competing interests}

The authors declare that they have no competing interests.

\section{Author details}

Department of Orthopedic Surgery, Inje University Busan Paik Hospital, 75, Bokji-ro, Busanjin-gu, Busan 47392, Republic of Korea. ${ }^{2}$ Department of Preventive Medicine, Korea University College of Medicine, Seoul, Republic of Korea. ${ }^{3}$ Department of Orthopedic Surgery, Dong-A University College of Medicine, Busan, Republic of Korea. ${ }^{4}$ Department of Orthopedic Surgery, Biomedical Research Institute, Pusan National University Hospital, Busan, Republic of Korea.

Received: 25 September 2019 Accepted: 20 January 2020

Published online: 12 February 2020

\section{References}

1. Corten K, Bourne RB, Charron KD, Au K, Rorabeck CH (2011) What works best, a cemented or cementless primary total hip arthroplasty?: Minimum 17-year followup of a randomized controlled trial. Clin Orthop Relat Res 469(1):209-217

2. Kim YH, Park JW, Kim JS (2017) The clinical outcome of computer-navigated compared with conventional knee arthroplasty in the same patients: a prospective, randomized, double-blind, long-term study. J Bone Joint Surg Am 99(12):989-996

3. Shan L, Shan B, Suzuki A, Nouh F, Saxena A (2015) Intermediate and longterm quality of life after total knee replacement: a systematic review and meta-analysis. J Bone Joint Surg Am 97(2):156-168

4. Baumgartner BT, Karas V, Kildow BJ, Cunningham DJ, Klement MR, Green CL, Attarian DE, Seyler TM. Inpatient consults and complications during primary total joint arthroplasty in a bundled care model. J Arthroplasty. 2018;33(4):973-5.

5. Cancienne JM, Kandahari AM, Casp A, Novicoff W, Browne JA, Cui Q, Werner BC (2017) Complication rates after total hip and knee arthroplasty in patients with hepatitis c compared with matched control patients. J Am Acad Orthop Surg 25(12):e275-e281.

6. George J, Chughtai M, Khlopas A, Klika AK, Barsoum WK, Higuera CA, Mont MA. Readmission, reoperation, and complications: total hip vs total knee Arthroplasty. J Arthroplasty. 2018;33(3):655-60.

7. Baker PN, Deehan DJ, Lees D, Jameson S, Avery PJ, Gregg PJ, Reed MR (2012) The effect of surgical factors on early patient-reported outcome measures (proms) following total knee replacement. J Bone Joint Surg $\mathrm{Br}$ 94(8):1058-1066

8. Hustedt JW, Goltzer O, Bohl DD, Fraser JF, Lara NJ, Spangehl MJ (2017) Calculating the cost and risk of comorbidities in total joint arthroplasty in the United States. J Arthroplast 32(2):355-361.e351

9. Jiang SL, Schairer WW, Bozic KJ (2014) Increased rates of periprosthetic joint infection in patients with cirrhosis undergoing total joint arthroplasty. Clin Orthop Relat Res 472(8):2483-2491

10. Zhu Y, Zhang F, Chen W, Liu S, Zhang Q, Zhang Y (2015) Risk factors for periprosthetic joint infection after total joint arthroplasty: a systematic review and meta-analysis. J Hosp Infect 89(2):82-89

11. Abbott KC, Bucci JR, Agodoa LY (2003) Total hip arthroplasty in chronic dialysis patients in the United States. J Nephrol 16(1):34-39

12. Coresh J, Selvin E, Stevens LA, Manzi J, Kusek JW, Eggers P, Van Lente F, Levey AS (2007) Prevalence of chronic kidney disease in the United States. JAMA 298(17):2038-2047

13. Jha V, Garcia-Garcia G, Iseki K, Li Z, Naicker S, Plattner B, Saran R, Wang AY, Yang CW (2013) Chronic kidney disease: global dimension and perspectives. Lancet 382(9888):260-272

14. Warth LC, Pugely AJ, Martin CT, Gao Y, Callaghan JJ (2015) Total joint arthroplasty in patients with chronic renal disease: is it worth the risk? J Arthroplast 30(9 Suppl):51-54

15. Erkocak OF, Yoo JY, Restrepo C, Maltenfort MG, Parvizi J (2016) Incidence of infection and inhospital mortality in patients with chronic renal failure after total joint arthroplasty. J Arthroplast 31(11):2437-2441

16. Fukunishi S, Fukui T, Nishio S, Imamura F, Yoh K, Yoshiya S (2009) Results of total hip arthroplasty for dialysis arthropathy in long-term hemodialysis patients. J Orthop Sci 14(3):285-291

17. Himmelfarb J (2005) Hemodialysis complications. Am J Kidney Dis 45(6): $1122-1131$

18. Tejwani NC, Schachter AK, Immerman I, Achan P (2006) Renal osteodystrophy. J Am Acad Orthop Surg 14(5):303-311

19. Maradit Kremers $H$, Schleck CD, Lewallen EA, Larson DR, Van Wijnen AJ, Lewallen DG (2017) Diabetes mellitus and hyperglycemia and the risk of aseptic loosening in total joint arthroplasty. J Arthroplast 32(9S):S251-S253 
20. Mathew A, Devereaux PJ, O'Hare A, Tonelli M, Thiessen-Philbrook H, Nevis IF, lansavichus AV, Garg AX (2008) Chronic kidney disease and postoperative mortality: a systematic review and meta-analysis. Kidney Int 73(9):1069-1081

21. Deegan BF, Richard RD, Bowen TR, Perkins RM, Graham JH, Foltzer MA (2014) Impact of chronic kidney disease stage on lower-extremity arthroplasty. Orthopedics 37(7):e613-e618

22. Kuo LT, Lin SJ, Chen CL, Yu PA, Hsu WH, Chen TH (2017) Chronic kidney disease is associated with a risk of higher mortality following total knee arthroplasty in diabetic patients: a nationwide population-based study. Oncotarget 8(59):100288-100295

23. Miric A, Inacio MC, Namba RS (2014) The effect of chronic kidney disease on total hip arthroplasty. J Arthroplast 29(6):1225-1230

24. Miric A, Inacio MCS, Namba RS (2014) Can total knee arthroplasty be safely performed in patients with chronic renal disease? Acta Orthop 85(1):71-78

25. Patterson JT, Tillinghast K, Ward D (2018) Dialysis dependence predicts complications, intensive care unit care, length of stay, and skilled nursing needs in elective primary total knee and hip arthroplasty. J Arthroplast 33(7):2263-2267

26. Ponnusamy KE, Jain A, Thakkar SC, Sterling RS, Skolasky RL, Khanuja HS (2015) Inpatient mortality and morbidity for dialysis-dependent patients undergoing primary total hip or knee arthroplasty. J Bone Joint Surg Am 97(16):1326-1332

27. Bedard NA, DeMik DE, Dowdle SB, Owens JM, Liu SS, Callaghan JJ (2018) Does preoperative opioid use increase the risk of early revision total hip arthroplasty? J Arthroplasty 33(7):S154-S156

28. Bedard NA, DeMik DE, Dowdle SB, Owens JM, Liu SS, Callaghan JJ (2018) Preoperative opioid use and its association with early revision of total knee arthroplasty. J Arthroplasty 33(11):3520-3523

29. Boniello AJ, Simon MS, Emenari CC, Courtney PM (2018) Complications and mortality following total hip arthroplasty in the octogenarians: an analysis of a national database. J Arthroplasty 33(7):S167-S171

30. Cavanaugh PK, Chen AF, Rasouli MR, Post ZD, Orozco FR, Ong AC (2016) Complications and mortality in chronic renal failure patients undergoing total joint arthroplasty: a comparison between dialysis and renal transplant patients. J Arthroplast 31(2):465-72

31. Kildow BJ, Agaba P, Moore BF, Hallows RK, Bolognesi MP, Seyler TM. Postoperative impact of diabetes, chronic kidney disease, hemodialysis, and renal transplant after total hip Arthroplasty. J Arthroplasty. 2017;32(9S):S135-S40 e1.

32. McCleery MA, Leach WJ, Norwood T (2010) Rates of infection and revision in patients with renal disease undergoing total knee replacement in scotland. J Bone Joint Surg Br 92(11):1535-1539

33. Kuo FC, Lin PC, Lu YD, Lee MS, Wang JW (2017) Chronic kidney disease is an independent risk factor for transfusion, cardiovascular complication, and thirty-day readmission in minimally invasive total knee arthroplasty. J Arthroplast 32(5):1630-1634

34. Lizaur-Utrilla A, Martinez-Mendez D, Collados-Maestre I, Marco-Gomez L, Lopez-Prats FA (2016) Elective total knee arthroplasty in patients with endstage renal disease: Is it a safe procedure? J Arthroplast 31(10):2152-2155

35. Marya SKS, Amit P, Singh C (2016) Impact of charlson indices and comorbid conditions on complication risk in bilateral simultaneous total knee arthroplasty. Knee 23(6):955-59

36. Nikkinen $\mathrm{O}$, Nieminen T, Alahuhta S, Ohtonen P, Vakkala M. Chronic kidney disease and acute kidney injury in arthroplasty patients over 65 years of age. Acta Anaesthesiol Scand. 2019;63(7):859-70.

37. National Kidney F (2002) K/doqi clinical practice guidelines for chronic kidney disease: evaluation, classification, and stratification. Am J Kidney Dis 39(2 Suppl 1):S1-S266

38. Bozic KJ, Lau E, Ong K, Chan V, Kurtz S, Vail TP, Rubash HE, Berry DJ (2014) Risk factors for early revision after primary total hip arthroplasty in Medicare patients. Clin Orthop Relat Res 472(2):449-454

39. Inneh IA, Lewis CG, Schutzer SF (2014) Focused risk analysis: regression model based on 5,314 total hip and knee arthroplasty patients from a single institution. J Arthroplasty 29(10):2031-2035

40. Singh JA, Lewallen DG (2013) Medical and psychological comorbidity predicts poor pain outcomes after total knee arthroplasty. Rheumatology (United Kingdom) 52(5):916-923

41. Quan H, Sundararajan V, Halfon P, Fong A, Burnand B, Luthi JC, Saunders LD, Beck CA, Feasby TE, Ghali WA (2005) Coding algorithms for defining comorbidities in ICD-9-cm and ICD-10 administrative data. Med Care 43(11): 1130-1139
42. Charlson ME, Pompei P, Ales KL, MacKenzie CR (1987) A new method of classifying prognostic comorbidity in longitudinal studies: development and validation. J Chronic Dis 40(5):373-383

43. Elixhauser A, Steiner C, Harris DR, Coffey RM (1998) Comorbidity measures for use with administrative data. Med Care 36(1):8-27

44. Brown EA, Arnold IR, Gower PE (1986) Dialysis arthropathy: complication of long term treatment with haemodialysis. Br Med J (Clin Res Ed) 292(6514): 163-166

45. Parvizi J, Gehrke T, International Consensus Group on Periprosthetic Joint I (2014) Definition of periprosthetic joint infection. J Arthroplast 29(7):1331

46. Klatt BA, Steele GD, Fedorka CJ, Sanchez Al, Chen AF, Crossett LS (2013) Solid organ transplant patients experience high rates of infection and other complications after total knee arthroplasty. J Arthroplast 28(6):960-963

\section{Publisher's Note}

Springer Nature remains neutral with regard to jurisdictional claims in published maps and institutional affiliations.

\section{Ready to submit your research? Choose BMC and benefit from:}

- fast, convenient online submission

- thorough peer review by experienced researchers in your field

- rapid publication on acceptance

- support for research data, including large and complex data types

- gold Open Access which fosters wider collaboration and increased citations

- maximum visibility for your research: over $100 \mathrm{M}$ website views per year

At BMC, research is always in progress.

Learn more biomedcentral.com/submissions 